Beyond aesthetic judgment: Beauty increases moral standing

Christoph Klebl, Yin Luo, Brock Bastian

University of Melbourne

Corresponding author: Christoph Klebl, Melbourne School of Psychological Sciences, University of Melbourne, Redmond Barry Building, Parkville Campus, 3010 Melbourne, Australia, cklebl@student.unimelb.edu.au.

THIS MANUSCRIPT IS CURRENTLY UNDER PEER REVIEW 


\begin{abstract}
Researchers have identified several factors that may increase the moral standing people place on various entities (e.g., mind perception). We suggest perceptions of beauty also signal that targets possess moral standing and therefore are worthy of protection. In three studies, we found people attribute greater moral standing to beautiful (vs. ugly) animals (Study 1; Study 5a, pre-registered) and humans (Study 2). In an additional three studies, we found this effect also extends to non-sentient targets, that is, people perceive beautiful (vs. ugly) landscapes (Study 3) and buildings (Study 4; Study 5b, pre-registered) as possessing greater moral standing. Across all studies $(N=1,662)$, we found purity intuitions mediated the effect of beauty on moral standing, suggesting beauty increases the moral standing individuals place on targets through evoking moral intuitions of purity.
\end{abstract}

Keywords: beauty, aesthetic judgment, moral standing, purity 


\section{Beyond aesthetic judgment: Beauty increases moral standing}

Past research has identified several factors that contribute to whether we consider entities as morally mattering for their own sake — that is, perceive them as possessing moral standing (Goodwin, 2015). Mind perception, particularly perceiving targets as being capable of having sensations and feelings (Gray et al., 2012; Sytsma \& Machery, 2012), as well as emotional responses (e.g., gratitude, disgust, or contempt) and empathy (Tangney et al., 2007) has been linked to the degree to which individuals afford moral standing to various targets. Previous research suggests aesthetic perceptions are a further contributor to the moral standing individuals attribute to people (Dion et al., 1972; Langlois et al., 2000) and animals (Gunnthorsdottir, 2001; Landová et al., 2018; Marešová \& Frynta, 2008). Here, we propose that unlike mind perception and empathy which typically impacts on the moral standing

placed on humans or animals, aesthetic perceptions impact on the moral standing attributed to both sentient beings (humans and animals) and non-sentient targets (i.e., landscapes and works of architecture). As such, we examine whether beauty perceptions increase the moral standing of entities independently of whether they have the capacity to suffer. Furthermore, based on evidence linking beauty perceptions and purity intuitions (Diessner et al., 2013; Klebl et al., 2020), as well as evidence suggesting that purity intuitions increase moral standing attributions (Feinberg \& Willer, 2013; Frimer et al., 2015; Haidt \& Joseph, 2004; Rottman et al., 2015), we propose that beauty increases moral standing attributions through evoking moral intuitions of purity.

\section{Beauty as a Contributor to Moral Standing}

An entity is attributed moral standing if it is perceived to morally matter for its own sake and not solely because of one's own interests or the interests of other moral patients (Sytsma \& Machery, 2012). People can attribute moral standing to humans and other animals (Goodwin, 2015), as well as to the natural environment (Stern \& Dietz, 1994). We propose 
that beauty judgments are one factor that leads people to attribute moral standing to various entities such as humans, animals, landscapes and perhaps even works of architecture.

Previous research suggests that beauty plays a role in human morality and may contribute to judgments of moral standing. People exhibit a range of positive judgments and prosocial behaviors toward physically attractive individuals. For instance, it has been revealed that people have the tendency to perceive physically attractive individuals, compared to unattractive individuals, as possessing socially desirable traits (Dion et al., 1972). Moreover, children were found to view attractive, compared to a less attractive, individuals as more trustworthy (Bascandziev \& Harris, 2014). Attractive individuals are also treated more positively than unattractive individuals - for example, attractive children are given greater attention and caregiving (Langlois et al., 2000). Similarly, perceived cuteness enhances behavioral carefulness (Sherman et al., 2009). This is further corroborated by findings suggesting that beauty increases animals' moral standing. For example, animals' attractiveness positively predicts their size in zoo populations (Marešová \& Frynta, 2008), support for their conservation (Gunnthorsdottir, 2001), and people's willingness to protect their species (Landová et al., 2018). People also experience greater disgust at the thought of eating cute animals compared to animals of average attractiveness (Rozin \& Ruby, 2020; Ruby \& Heine, 2012).

The finding that people attribute more moral standing to beautiful compared to ugly animals and humans is also consistent with theorizing and evidence suggesting beauty and morality are linked more generally. For example, Kant considered beauty to be the 'symbol of morality' (Kant, 1790/2000, p. 225) and Plotinus believed that virtue leads to the highest form of beauty through the purification of the soul (Gerson, 2017). Consistent with this, 'beautiful' is colexified with 'good' in at a least 101 languages, for instance, in ancient Greek ( $k a$ 'los; Rzymski et al., 2020). Furthermore, neuroimaging studies have revealed shared brain activity 
for facial attractiveness judgments and judgments of moral acts (e.g., "He rescued an abandoned dog"; Tsukiura \& Cabeza, 2010) and also suggest a link between beauty and morality which extends beyond human attractiveness. For example, beauty judgments of poems and judgments of moral statements (e.g., "It is false to wage war"; Avram et al., 2013), as well as beauty judgments of artworks and moral goodness judgments of actions (Heinzelmann et al., 2020), involve common neural networks.

\section{Beauty, Moral Standing and Purity}

While there is initial evidence suggesting that beauty judgments lead to moral standing attributions, no empirical work has investigated the specific mechanism through which beauty may increase the moral standing afforded to an entity, independently of other positive judgments. We propose that one reason beauty perceptions lead individuals to perceive targets as high in moral standing and therefore worthy of protection is because beauty evokes moral intuitions of purity.

Purity intuitions have been suggested to play an integral role in morality. One of the most prominent theoretical frameworks in moral psychology argues that purity intuitions are one of five or six moral intuitions underpinning human morality (Moral Foundations Theory; Haidt \& Joseph, 2004). They may have evolved from human concerns about pollution and degradation and are reflected in many cultural norms and practices (such as in sexual norms, hygiene practices, or meditation; Haidt \& Joseph, 2004). There is also evidence suggesting that purity intuitions can lead people to view entities as possessing moral standing. For example, purity intuitions have been argued to be a major contributor to moral concern for the environment (Rottman et al., 2015). Similarly, framing pro-environmental rhetoric in terms of purity increases pro-environmental attitudes in conservatives (Feinberg \& Willer, 2013). Further evidence for a link between purity intuitions and moral standing attributions was provided by research on sanctity perceptions which have been argued to underlie the 
same psychological mechanism as purity intuitions (Haidt, 2003; Haidt \& Graham, 2007). Viewing an object as sacred involves perceiving the entity as requiring protection, independently from its economic value or its utility with trade-offs between sacred value and instrumental value considered taboo (Baron \& Spranca, 1997; Haidt, 2003; Ruttan \& Nordgren, 2021; Tetlock et al., 2000). For example, people were found to perceive the mountain Cerro Torre as a sacred object that is worthy of protection (Frimer et al., 2015). Moreover, believing that nature is sacred increases environmental concern (Stern et al., 1999).

If perceptions of purity endow targets with moral standing, does beauty lead to perceptions of purity? There is indirect evidence suggesting that indeed beauty perceptions may evoke purity intuitions. Haidt (2003) argued that "purity vs. pollution" is a social dimension along which people can vary (e.g., a priest vs. a prostitute) and that elevation-an emotion involving, for instance, a warm feeling in the chest - is associated with witnessing individuals moving up this dimension. Specifically, acts of virtue or moral beauty have been argued to be the primary elicitors of elevation, suggesting that someone performing a morally beautiful act may be perceived as increasing their state purity (Diessner et al., 2013; Haidt, 2003). Based on this association, along with evidence that non-moral beauty activates shared brain areas with moral beauty (Wang et al., 2015), we suggest that the perception and experience of beauty may evoke purity intuitions.

In sum, there is indirect evidence suggesting that beauty may evoke purity intuitions. Furthermore, purity intuitions have been linked to people attributing moral standing to targets (Frimer et al., 2015; Rottman et al., 2015; Stern et al., 1999). Therefore, beauty perceptions may lead individuals to attribute moral standing to targets because beauty elicits intuitions of moral purity. This is also indirectly supported by research showing that ugly entities elicit disgust (Klebl et al., 2020) — and as such impurity perceptions — as well as evidence 
suggesting disgust may reduce the moral standing placed on entities (Oaten et al., 2011). For example, people avoid individuals with facial disfigurement, and this has been found to be mediated by disgust (Park et al., 2013; Ryan et al., 2012).

\section{The Present Studies}

Based on previous research suggesting beauty perceptions may lead people to view humans and other animals as possessing moral standing (Dion et al., 1972; Gunnthorsdottir, 2001; Landová et al., 2018; Langlois et al., 2000; Marešová \& Frynta, 2008), we investigated in six studies whether beauty perceptions increase the moral standing people place on a wide range of targets including non-sentient entities. We propose that the psychological mechanism through which beauty assigns moral standing to targets is through evoking moral intuitions of purity. Specifically, we hypothesized that individuals attribute more moral standing to beautiful (vs. ugly) animals (Studies $1 \& 5$ a) and humans (Study 2). We hypothesized that the effect of aesthetic judgments on moral standing attributions is independent from entities' sentience (i.e., not due to mind perception), also increasing the moral standing of non-sentient targets, that is, of landscapes (Study 3) and buildings (Studies $4 \& 5 b)$. Moreover, we hypothesized that this effect is mediated by perceptions of purity.

In Studies 1-4, we measured moral standing attributed to entities through an intuitive measure (i.e., expressed desire to protect). In two additional pre-registered studies, we sought to replicate findings that people assign greater moral standing to beautiful (vs. ugly) animals (Study 5a) and buildings (Study 5b), employing a more direct measure of moral standing that directly assessed whether the targets were perceived to matter for their own sake (Piazza et al., 2014). To buttress confidence in any observed effects, we contrasted our proposed pathway from beauty to moral standing attributions via purity with other possible pathways or explanations. Controlling for alternative explanations allowed us to demonstrate that beauty has a unique association with moral standing via purity perceptions rather than with 
positive perceptions more generally. First, we contrasted purity perceptions with perceived utility. Given the evolutionary function of beauty as responding to targets that have adaptive value (Dutton, 2009), beautiful targets might be perceived as having instrumental value (i.e., a beautiful landscape may be perceived as being of greater use than an ugly one). Perceptions of utility may also increase the desire to protect a target for self-interested motivations or for its benefits to other humans (cf. Stern \& Dietz, 1994). Therefore, utility may be an alternative pathway through which beauty leads to a desire to protect targets for motivations other than an entity's own sake. Second, we controlled for the perceived capacity to experience pain (in judgments of humans) in order to test whether the effects of beauty perceptions on moral standing were reducible to mind perception and specifically to moral patiency (Gray \& Wegner, 2009). As such, we controlled for whether the effects were due to harm intuitionsperceiving an entity as having the capacity for mental experience is one basis for caring about its suffering (Gray et al., 2012; Haidt \& Graham, 2007). Additionally, in the case of landscapes and buildings we controlled for perceived aliveness which is arguably most closely related to mind perception in sentient beings. We did not, however, control for other moral foundations (fairness, ingroup, and authority), because they cannot be straightforwardly applied to non-human entities that cannot reciprocate or form hierarchical group structures (Haidt \& Graham, 2007). Second, we controlled for experiences of inspiration as they have been linked to beauty (Thrash \& Elliot, 2003). This further allowed us to examine whether purity is a unique meditator of the predicted effect, distinct from other positive responses to beauty. Fourth, in the Studies $5 \mathrm{a}$ and $5 \mathrm{~b}$, we controlled for perceptions of rarity. Beauty judgments have been linked to averageness of entities and therefore beautiful (vs. ugly) entities may be perceived as less rare (Halberstadt \& Rhodes, 2000); and rarity has been shown to positively predict moral standing attributions (e.g., Tisdell et al., 2007). As such, rarity may be a negative mediator of the effect. Finally, we contrasted purity 
perceptions with negative emotions (disgust, fear and sadness) to control for the alternative hypothesis that ugliness reduces (instead of beauty increases) moral standing placed on targets (cf. Griffin \& Langlois, 2006). Specifically, the emotion disgust has been shown to be closely linked to ugliness judgments (Klebl et al., 2020) and thus may be a pathway through which ugliness judgments reduce entities' moral standing.

\section{Study 1}

In Study 1, we investigated whether people attribute more moral standing to beautiful animals than to ugly animals. Furthermore, we tested whether this effect was mediated by purity intuitions.

\section{Method}

Participants. Because of the unavailability of tools to compute required sample sizes for within-subject mediations, we used the R package Monte Carlo Power Analysis for Indirect Effects (Schoemann et al., 2017) as a simple heuristic. We determined that a sample size of $N=132$ would allow for an $80 \%$ chance of detecting a medium effect $(r=.35 ; \alpha=$ .05 , two-tailed) in a simple between-subject mediation analysis. In order to secure sufficient power, we recruited nearly twice as large a sample of 250 participants living in the USA from Amazon's Mechanical Turk (MTurk) in return for US\$0.60. The final sample comprised 252 participants $\left(41.7 \%\right.$ female; $M_{\text {age }}=35.4, S D=10.2$, range $\left.=19-68\right){ }^{1}$

Procedure and Materials. After providing informed consent, participants were randomly presented with six images of animals (birds, fish, and butterflies) that were taken from [Citation blinded]. There was a beautiful and an ugly variant of each animal and pairs were matched in size and color.

\footnotetext{
${ }^{1}$ In all studies, sample sizes were determined before any data analysis. A larger final sample compared to the recruited sample indicates that some participants did not submit the completion code on MTurk.
} 
Manipulation checks. Participants were asked to rate the extent to which they found each animal beautiful (This [animal] is beautiful) and ugly.

Moral standing. In order to measure the moral standing that participants attribute to animals, they were asked to rate the extent to which they felt a desire to protect the respective animal (Ifeel a desire to protect this [animal]). Previous literature suggests that protection motivations are closely related to the moral standing that individuals assign to entities (Rottman et al., 2015) and protection motivations have been used as a measure of moral standing (Piazza et al., 2014).

Purity and control variables. To test whether the depicted animals evoked purity intuitions, participants were asked to rate the extent to which the respective animals made them think of something pure (This [animal] makes me think of something pure).

Additionally, in order to control for alternative mediators, participants rated the degree to which they found the animals useful, inspiring, and the degree to which they made them feel disgusted, sad and frightened. All variables were assessed with single-item measures using an 11-point Likert scale $(0=$ not at all, $10=$ very much so $)$ and the order in which the items were presented was randomized. ${ }^{2}$

\section{Results}

Two participants were excluded from the analysis due to failing the attention check. ${ }^{3}$ Missing data were deleted list-wise. ${ }^{4}$

\footnotetext{
${ }^{2}$ Individual difference measures were used for exploratory purposes (see supplemental materials).

${ }^{3}$ Additional analyses revealed that in all studies excluding participants had no substantive impact on the results.

${ }^{4}$ The data and materials of all studies are available at https://osf.io/uqgt4/?view_only=402591826a5040f8a24d948df3a346d7.
} 
Manipulation checks. Paired samples $t$-tests were conducted to compare perceived beauty and ugliness between the beautiful and ugly conditions. Animals in the beauty condition $(M=7.7, S D=1.9)$ were rated as significantly more beautiful than in the ugliness condition $(M=3.2, S D=2.6), t(248)=26.40, p<.001$. Further, animals in the beauty condition $(M=0.8, S D=1.5)$ were rated as significantly less ugly than animals in the ugliness condition $(M=5.5, S D=2.6), t(248)=-25.00, p<.001$. While there were significant differences in both beauty and ugliness judgments between the conditions, it is worth noting that ugly images were rated to be only slightly above the mid-point of the scale in terms of their ugliness.

Mediation analysis. We conducted a repeated-measures mediation analysis with condition (beauty vs. ugliness) as the predictor, moral standing as the dependent variable, and purity as the mediator, using the MEMORE macro (5,000 bootstrap samples; Montoya $\&$ Hayes, 2017). ${ }^{5}$

Overall, the model was significant (beauty $=1$; ugliness $=0), F(2,247)=89.84, p<$ $.001, R^{2}=.42$. As predicted, participants afforded more moral standing (i.e., an increased desire to protect) to beautiful animals compared to ugly animals, $b=1.98, S E=0.01, t(249)=$ $202.01,95 \% \mathrm{CI}=[1.96,2.00]$. Also as predicted, condition positively predicted perceived purity, $b=3.15, S E=0.18,95 \% \mathrm{CI}=[2.80,3.50]$, and purity positively predicted moral standing, $b=0.56, S E=0.04,95 \% \mathrm{CI}=[0.47,0.64]$. Results revealed a significant indirect effect of condition on moral standing through perceptions of purity, $b=1.76, S E=0.17$,

\footnotetext{
${ }^{5}$ Multicollinearity was not an issue in any of the studies. All variance inflation factors were $<2.7$. Means and standard deviations of all variables as well as repeated-measures correlations among all variables for each of the studies are reported in the supplemental materials.
} 
$95 \% \mathrm{CI}=[1.44,2.10]$. There was no direct effect of the condition on moral standing, $b=$ $0.22, S E=0.18, t(247)=1.25,95 \% \mathrm{CI}=[-0.13,0.57]$.

When adding perceived utility, inspiration, disgust, sadness, and fear as parallel mediators to the model (see Figure 1), the indirect effect through perceptions of purity remained significant, $b=0.79, S E=0.23,95 \% \mathrm{CI}=[0.32,1.21]$. Furthermore, perceived utility was also a significant mediator of the effect of beauty (vs. ugliness) on moral standing, $b=0.50, S E=0.22,95 \% \mathrm{CI}=[0.08,0.93]$. Inspiration, $b=0.40, S E=0.24,95 \% \mathrm{CI}=[-0.04$, $0.91]$, disgust, $b=0.20, S E=0.21,95 \% \mathrm{CI}=[-0.16,0.65]$, sadness, $b=-0.04, S E=0.13$, $95 \% \mathrm{CI}=[-0.30,0.20]$, and fear, $b=0.19, \mathrm{SE}=0.15,95 \% \mathrm{CI}=[-0.12,0.46]$, however, were non-significant mediators of the effect. ${ }^{6}$

\section{Study 2}

In Study 1, we found that people afforded more moral standing to beautiful animals compared to ugly animals, and that this was mediated by purity perceptions. This effect remained significant when controlling for other positive perceptions. Furthermore, we found an additional pathway through perceptions of utility. In Study 2, we investigated whether beauty may also impact on the moral standing assigned to humans. Although humans are mostly viewed as possessing high levels of moral standing, research has shown that subtle variations also exist (Bastian et al., 2011). Additionally, we explored whether any effects of beauty on moral standing are independent of mind perception which has been previously linked to the moral standing assigned to humans (Gray et al., 2012).

\footnotetext{
${ }^{6}$ In order to rule out that the effects can be explained by constructs other than beauty perceptions, we conducted for Studies 1-4 and Study 5b repeated-measures mediation analyses testing the indirect effects of condition (beauty vs. ugliness) on moral standing via beauty ratings. In all studies, beauty perceptions fully accounted for the total effect of condition on moral standing (see supplemental materials).
} 


\section{Figure 1}

The mediation model (Study 1) with beauty (vs. ugliness) as the independent variable; moral standing as the dependent variable; and purity, utility, inspiration, disgust, sadness, and fear as mediators.

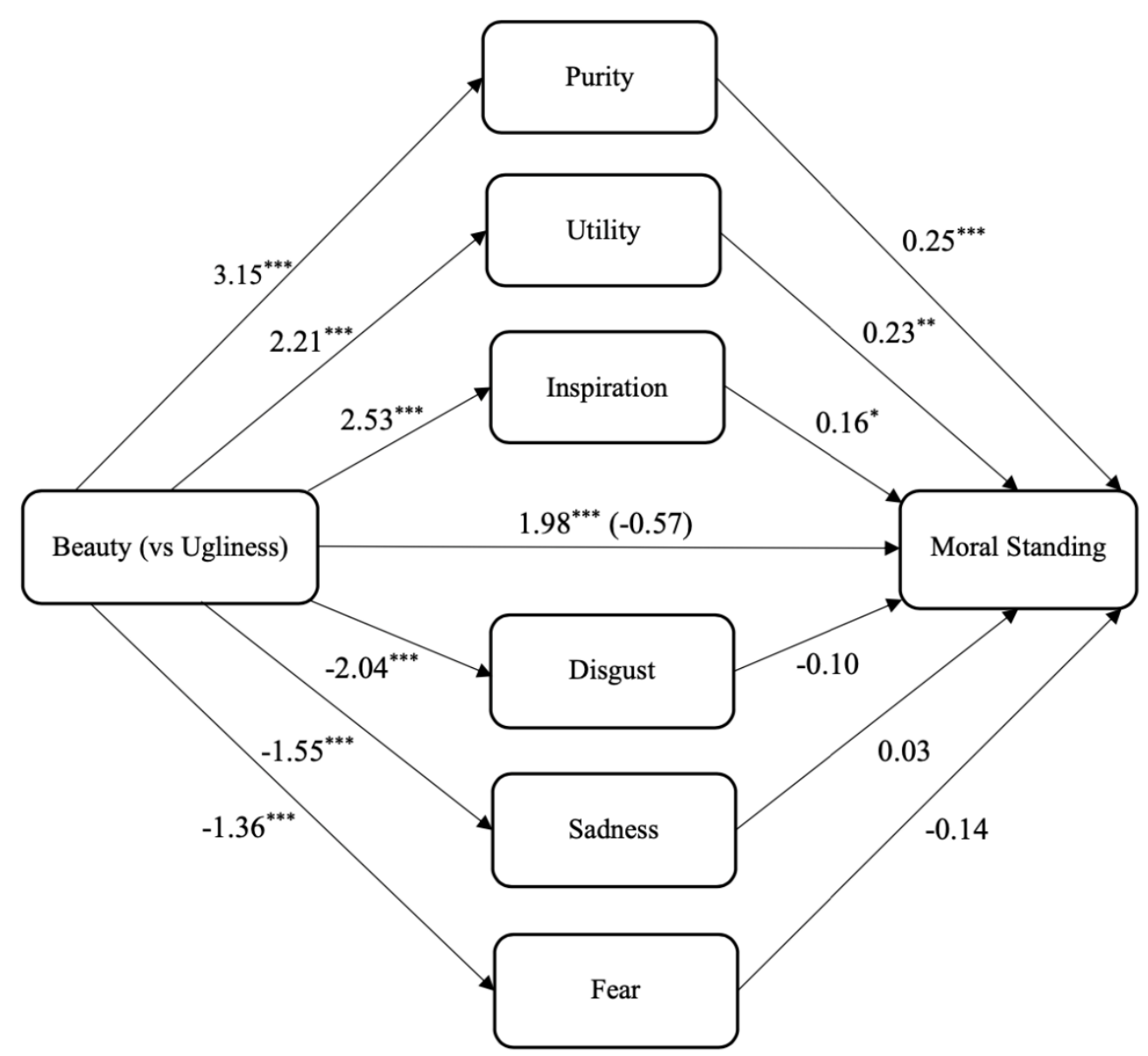

Note. ${ }^{*} p<.05 .{ }^{* *} p<.01 .{ }^{* * *} p<.001$. For $S E$ 's and confidence intervals see supplemental materials.

\section{Method}

Participants. Using Monte Carlo simulations (Schoemann et al., 2017) as a heuristic with two parallel mediators and the path coefficients found in Study 1, we determined that a sample size of $N=110(\alpha=.05$, two-tailed $)$ was required for a power of .80 . However, due to a potential social desirability bias in attributing moral standing to human targets, we expected the effect sizes to be possibly smaller. Therefore, in order to secure sufficient power, we 
recruited a three times larger sample of 300 participants living in the USA from MTurk in return for US\$0.85. Three hundred five participants $\left(42.6 \%\right.$ female; $M_{a g e}=36.2, S D=11.2$, range $=19-73$ ) completed the survey.

Procedure and Materials. Participants were randomly presented with 12 pictures of human faces (six attractive and six unattractive) taken from the Chicago Face Database (Ma et al., 2015). Based on norming data provided by Ma et al. (2015), we selected the most attractive and the most unattractive faces of each sex (male and female) and each of three ethnicities (Asian, Black, and White; see Figure 2). However, we excluded faces with potential disease cues (e.g., sweatiness). All faces depicted neutral facial expressions. As in Study 1, participants rated the extent to which they found each face beautiful, pure, inspiring, ugly, disgusting, fearful, and saddening, and the extent to which they had the desire to protect the respective individual. In order to measure perceived utility more precisely, we asked participants to rate the extent to which the individuals are useful to them. Furthermore, in order to control for the potential effect of unattractive individuals being perceived as having less mind, and therefore, as possessing less moral standing, we additionally asked participants to judge the extent to which the depicted individuals could experience pain (This person can experience pain; Gray et al., 2012; Gray \& Wegner, 2009). All variables were measured with single items and were assessed on an 11-point Likert scale $(0=$ not at all, $10=$ very much so $)$.

\section{Results}

Thirteen participants were excluded from the analyses because they failed the attention check, and four because they did not consent to their data being used.

Manipulation checks. Paired samples $t$-tests showed that attractive faces $(M=6.3$, $S D=1.9)$ were rated as significantly more beautiful than unattractive faces $(M=2.9, S D=$ $2.4), t(287)=26.61, p<.001$. Furthermore, attractive faces $(M=1.4, S D=1.9)$ were rated as significantly less ugly than unattractive faces $(M=4.8, \mathrm{SD}=2.6), t(287)=-21.98, p<.001$. 
Similar to Study 1, while there were significant differences in both beauty and ugliness judgments between the conditions, unattractive faces were rated slightly below the mid-point of the scale in terms of their ugliness.

Mediation analysis. A within-subject repeated-measures mediation analysis with condition (beauty vs. ugliness) as the predictor, moral standing as the dependent variable, and purity as the mediator was conducted (5,000 bootstrap samples; Montoya \& Hayes, 2017).

Overall, the model was significant (beauty $=1$; ugliness $=0), F(2,285)=90.83, p<$ $.001, R^{2}=.39$. As predicted, people attributed more moral standing (i.e., an increased desire to protect) to attractive individuals compared with unattractive individuals, $b=0.84, S E=$ $0.01, t(287)=169.11,95 \% \mathrm{CI}=[0.84,0.85]$. Also as predicted, beauty (vs. ugliness) positively predicted perceived purity, $b=1.38, S E=0.09,95 \% \mathrm{CI}=[1.20,1.56]$, and purity positively predicted moral standing, $b=0.58, S E=0.04,95 \% \mathrm{CI}=[0.49,0.66]$. Results revealed a significant indirect effect of condition on moral standing through perceptions of purity, $b=0.80, S E=0.08,95 \% \mathrm{CI}=[0.64,0.96]$. There was no direct effect of condition on moral standing, $b=0.05, S E=0.09, t(285)=0.05,95 \% \mathrm{CI}=[-0.13,0.22]$.

Perceptions of purity remained a significant mediator when including perceived utility, inspiration, perceived pain, disgust, sadness, and fear into the model (see Table 1). ${ }^{7}$ Furthermore, perceived utility positively, and sadness negatively mediated the effect of beauty on moral standing. Together, they fully mediated the effect. However, inspiration, perceived pain, disgust, and fear, were non-significant mediators of the effect.

\footnotetext{
${ }^{7}$ Having provided a figure for Study 1 to highlight the conceptual approach, we use tables for the following studies to increase the clarity of the information.
} 


\section{Table 1}

Within-subject repeated-measures mediation analyses with condition (beautiful vs. ugly) as independent variable; moral standing as dependent variable; and purity, utility, inspiration, pain, disgust, sadness and fear as mediators (Study 2).

\begin{tabular}{lcccccccccc}
\hline \multicolumn{1}{c}{ Condition on Mediator } & \multicolumn{3}{c}{ Mediator on Moral Standing } & \multicolumn{3}{c}{ Indirect effect } \\
\hline Mediator & $b$ & $S E$ & $C I$ & $b$ & $S E$ & $C I$ & $b$ & $S E$ & $C I$ \\
\hline Purity & $1.39^{* * *}$ & 0.09 & {$[1.21,1.57]$} & $0.39^{* * *}$ & 0.06 & {$[0.26,0.51]$} & 0.54 & 0.11 & {$[0.30,0.73]$} \\
Utility & $1.14^{* * *}$ & 0.08 & {$[0.98,1.31]$} & $0.18^{* *}$ & 0.06 & {$[0.06,0.31]$} & 0.21 & 0.09 & {$[0.05,0.40]$} \\
Inspiration & $1.27^{* * *}$ & 0.10 & {$[1.09,1.46]$} & $0.13^{*}$ & 0.60 & {$[0.01,0.24]$} & 0.16 & 0.09 & {$[-0.005,0.37]$} \\
Pain & -0.03 & 0.06 & {$[-0.15,0.09]$} & $0.20^{* *}$ & 0.06 & {$[0.07,0.32]$} & -0.01 & 0.01 & {$[-0.04,0.02]$} \\
Disgust & $-1.43^{* * *}$ & 0.11 & {$[-1.64,-1.22]$} & -0.07 & 0.06 & {$[-0.20,0.05]$} & 0.10 & 0.11 & {$[-0.11,0.31]$} \\
Sadness & $-1.05^{* * *}$ & 0.10 & {$[-1.24,-0.85]$} & $0.22^{* * *}$ & 0.05 & {$[0.12,0.32]$} & -0.23 & 0.08 & {$[-0.38,-0.08]$} \\
Fear & $-0.87^{* * *}$ & 0.08 & {$[-1.02,-0.72]$} & $-0.15^{*}$ & 0.07 & {$[-0.29,-0.003]$} & 0.13 & 0.09 & {$[-0.04,0.31]$} \\
Total effect of condition on moral standing: & & & & & $0.85^{* * *}$ & 0.01 & {$[0.84,0.86]$} \\
Direct effect of condition on moral standing: & & & & -0.06 & 0.09 & {$[-0.24,0.12]$}
\end{tabular}

Model summary: $F(14,271)=20.37, p<.001, R^{2}=.51$

Note. $\mathrm{CI}=95 \%$ Confidence Interval. ${ }^{*} p<.05 .{ }^{* *} p<.01 .{ }^{* * *} p<.001$ 


\section{Figure 2}

Sample images used in Study 2 (Ma et al., 2015). Attractive individuals are displayed in the left column and unattractive individuals are displayed in the right column.
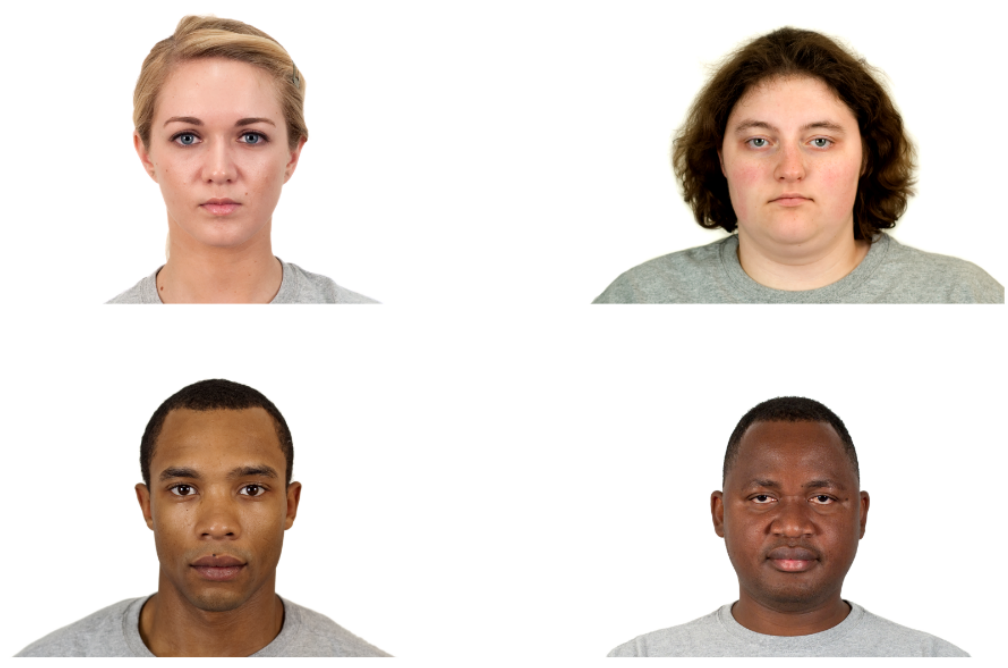

\section{Study 3}

Studies 1 and Study 2 found that individuals afford moral standing to beautiful humans and animals through evoked purity intuitions. We also found that people want to protect beautiful humans and animals because of their instrumental value (as well as a negative pathway through sadness in human faces, possibly due to experiencing pity in response to unattractive people; see Klebl et al., 2020). Overall, however, these effects were not explained by mind perception which has been the focus of previous work examining sources of motivation for protecting other people from harm (Gray et al., 2012). In Study 3, we further investigated whether people also attribute moral standing to beautiful targets that do not have sentience and mental capabilities (i.e., landscapes).

\section{Method}

Participants. Based on the determination of sample size using the path coefficients found in Study 1 (see above), we recruited 300 participants living in the USA from MTurk in 
return for US\$0.65. Three hundred three participants $\left(40.9 \%\right.$ female; $M_{a g e}=35.9, S D=11.9$, range $=18-71)$ completed the survey.

Procedure and Materials. Participants were presented with eight pictures of landscapes. For each type of landscape (lakes, mountains, fields, and forests), pairs of beautiful and ugly landscapes with matched image characteristics (i.e., size, surroundings, and angle of view) and which showed no signs of contamination were selected. The images were selected from Google images by research assistants and their differences in perceived beauty were validated in a pilot study $(N=58)$. The same items as in Study 2 were used. However, similar to mind perception in humans, individuals may have less desire to protect landscapes due to perceiving them as being less alive. Therefore, we additionally asked participants to rate the extent to which the landscapes are alive. All stimuli and items were presented in a random order.

\section{Results}

Six participants were excluded from the analysis because they failed the attention check. Missing data were deleted list-wise.

Manipulation checks. Paired samples $t$-tests revealed that beautiful landscapes $(M=$ 9.0, $S D=1.3)$ were rated as significantly more beautiful than ugly landscapes $(M=5.5, S D=$ $2.4), t(296)=28.04, p<.001$. Further, beautiful landscapes $(M=0.3, S D=0.8)$ were rated as significantly less ugly than ugly landscapes $(M=2.5, S D=2.0), t(296)=-19.41, p<.001$. Similar to previous studies, while the beautiful landscapes were rated as high in beauty, ugly landscapes were rated as below the mid-point of the scale in ugliness. Furthermore, ugly images were rated as above the mid-point on the scale in beauty.

Mediation analysis. A repeated-measures mediation analysis as in the previous studies was conducted. The model was significant (beauty $=1$; ugliness $=0), F(2,294)=$ 83.16, $p<.001, R^{2}=.36$. As predicted, participants attributed more moral standing to 
beautiful compared to ugly landscapes, $b=1.92, S E=0.01, t(296)=315.97,95 \% \mathrm{CI}=[1.90$, 1.93]. Also as predicted, condition positively predicted perceived purity, $b=2.83, S E=0.12$, $95 \% \mathrm{CI}=[2.60,3.05]$, and purity positively predicted moral standing, $b=0.56, S E=0.04$, $95 \% \mathrm{CI}=[0.47,0.64]$. Results revealed a significant indirect effect of condition on moral standing through perceptions of purity, $b=1.57, S E=0.16,95 \% \mathrm{CI}=[1.27,1.89]$. There was also a direct effect of condition on moral standing, $b=0.34, S E=0.15, t(294)=2.26,95 \% \mathrm{CI}$ $=[0.04,0.64]$.

When adding perceived utility, inspiration, aliveness, disgust, sadness, and fear as parallel mediators to the model, the indirect effect of beauty (vs. ugliness) on moral standing via perceptions of purity remained significant (see Table 2). Furthermore, perceived utility, inspiration, and aliveness positively mediated the effect of beauty on moral standing. Disgust, sadness, and fear, however, were non-significant mediators.

\section{Study 4}

In the previous studies, we found that people attribute more moral standing to both sentient and non-sentient beautiful targets (compared to ugly targets) and that purity and perceived utility consistently and independently mediated this effect. Furthermore, for landscapes, we found that aliveness is an additional pathway. In order to further explore whether people attribute moral standing to beautiful targets across all domains, in Study 4, we investigated whether individuals also place moral standing on non-organic targets (i.e., buildings) through evoked purity intuitions. Based on previous research that found ugliness judgments are linked to disgust responses even in buildings (Klebl et al., 2020), we hypothesized that purity perceptions may "spill-over" to non-organic entities. Moreover, as people may be more inclined to protect historical buildings, we controlled for perceived age of the building. 


\section{Table 2}

Within-subject repeated-measures mediation analysis with condition (beautiful vs. ugly) as independent variable; moral standing as dependent variable; and purity, utility, inspiration, aliveness, disgust, sadness and fear as mediators (Study 3).

\begin{tabular}{lccccccccc}
\hline & \multicolumn{3}{c}{ Condition on Mediator } & \multicolumn{3}{c}{ Mediator on Moral Standing } & \multicolumn{3}{c}{ Indirect effect } \\
\hline Mediator & $b$ & $S E$ & $C I$ & $b$ & $S E$ & $C I$ & $b$ & $S E$ & $C I$ \\
\hline Purity & $2.83^{* * *}$ & 0.12 & {$[2.60,3.05]$} & $0.21^{* * *}$ & 0.06 & {$[0.09,0.32]$} & 0.58 & 0.21 & {$[0.13,0.97]$} \\
Utility & $1.34^{* * *}$ & 0.09 & {$[1.16,1.51]$} & $0.21^{* *}$ & 0.07 & {$[0.08,0.34]$} & 0.29 & 0.12 & {$[0.05,0.55]$} \\
Inspiration & $2.94^{* * *}$ & 0.12 & {$[2.70,3.18]$} & $0.15^{* *}$ & 0.05 & {$[0.04,0.25]$} & 0.43 & 0.21 & {$[0.05,0.88]$} \\
Aliveness & $1.49^{* * *}$ & 0.10 & {$[1.29,1.69]$} & $0.27^{* * *}$ & 0.06 & {$[0.15,0.38]$} & 0.40 & 0.11 & {$[0.19,0.62]$} \\
Disgust & $-0.82^{* * *}$ & 0.07 & {$[-0.96,-0.67]$} & -0.01 & 0.10 & {$[-0.21,0.18]$} & 0.01 & 0.09 & {$[-0.17 .0 .18]$} \\
Sadness & $-1.10^{* * *}$ & 0.09 & {$[-1.28,-0.93]$} & -0.02 & 0.07 & {$[-0.17,0.13]$} & 0.02 & 0.09 & {$[-0.17,0.19]$} \\
Fear & $-0.74^{* * *}$ & 0.08 & {$[-0.89,0.58]$} & -0.03 & 0.08 & {$[-0.18,0.13]$} & 0.02 & 0.07 & {$[-0.12,0.16]$} \\
Total effect of condition on moral standing: & & & & & $1.92^{* * *}$ & 0.01 & {$[1.90,1.93]$} \\
Direct effect of condition on moral standing: & & & & 0.18 & 0.14 & {$[-0.11,0.46]$}
\end{tabular}

Model summary: $F(14,282)=23.93, p<.001, R^{2}=.54$

Note. $\mathrm{CI}=95 \%$ Confidence Interval. ${ }^{*} p<.05 .{ }^{* *} p<.01 .{ }^{* * *} p<.001$. 


\section{Method}

Participants. Consistent with the previous two studies, we recruited 300 participants living in the USA from MTurk in return for US\$0.70. Three hundred two participants $(42.7 \%$ female; $M_{\text {age }}=36.0, S D=11.0$, range $\left.=19-70\right)$ completed the survey.

Procedure and Materials. Participants were randomly presented with four pairs of images that depicted buildings. The images were selected from Google images by research assistants. Within each pair, the buildings varied in their degree of their beauty (tested in a pilot study, $N=51$ ), were matched in size and color, and did not show cues of contamination. The same items as in Study 3 were used. Additionally, we asked participants to indicate how old they guessed each building to be on a slider ranging from 0 to 100 years.

\section{Results}

Six participants were excluded because they failed the attention check, and five because they did not consent to their data being used. Missing data were deleted list-wise.

Manipulation checks. Paired samples $t$-tests showed that beautiful buildings $(M=$ $6.55, S D=1.80)$ were rated as significantly more beautiful than ugly buildings $(M=3.38, S D$ $=2.29), t(289)=25.01, p<.001$. Furthermore, beautiful buildings $(M=1.57, S D=1.70)$ were perceived to be significantly less ugly than ugly buildings $(M=5.15, S D=2.32), t(289)$ $=-25.35, p<.001$. Similar to the previous studies, the ugliness ratings of the ugly images were only slightly above the mid-point of the scale.

Mediation analysis. A mediation analysis as in the previous studies was conducted. Overall, the model was significant, $F(2,287)=92.66, p<.001, R^{2}=.39$. As predicted, there was a significant total effect of condition (beauty $=1$; ugliness $=0$ ) on moral standing, $b=$ $2.11, S E=0.01, t(289)=289.85,95 \% \mathrm{CI}=[2.11,2.14]$. Furthermore, as predicted, condition positively predicted perceived purity, $b=2.62, S E=0.12,95 \% \mathrm{CI}=[2.39,2.85]$, and purity positively predicted moral standing, $b=0.66, S E=0.05,95 \% \mathrm{CI}=[0.56,0.75]$. Results 
revealed a significant indirect effect of condition on moral standing through perceptions of purity, $b=1.72, S E=0.15,95 \% \mathrm{CI}=[1.43,2.02]$. There was also a direct effect of condition on moral standing, $b=0.39, S E=0.16, t(287)=2.46,95 \% \mathrm{CI}=[0.08,0.71]$.

Perceptions of purity remained a significant mediator when including perceived utility, inspiration, aliveness, perceived age, disgust, sadness, and fear as parallel mediators in the model (see Table 3). Furthermore, perceived utility, inspiration, and the perceived age of the building were also significant positive mediators of the effect of beauty (vs. ugliness) on moral standing. While the pathway through inspiration suggests that beautiful (vs. ugly) buildings were perceived to be more worthy of protection because they were found to be inspiring, the age of the buildings may mediate effect because it is linked to the cultural value associated with historical buildings. Aliveness, disgust, sadness, and fear, however, nonsignificantly mediated this effect.

\section{Study 5a}

In previous studies, we measured the assignment of moral standing to targets through the expressed desire to provide protection (Rottman et al., 2015). While drawing on indirect measures is useful for capturing intuitive moral standing attributions, it could be argued that we did not directly measure judgments about the moral standing of targets. Therefore, in Study 5a, we conceptually replicated Study 1 but employed a measure explicitly assessing whether animals matter for their own sake (Sytsma \& Machery, 2012). Moreover, we used a different set of stimuli, improved our measures of purity and utility, and controlled for the perceived rarity of the animals.

\section{Method}

Participants. Consistent with previous studies, we recruited 300 participants $(62.7 \%$ female; $M_{\text {age }}=39.7, S D=12.7$, range $=18-70$ ). Participants living in the UK were recruited 
from Prolific in return for $£ 0.50$. The pre-registration can be accessed at https://aspredicted.org/blind.php? $x=$ ep32jn.

Procedure and Materials. As part of an unrelated study, perceived beauty of all images in the Animal Images Database (Possidónio et al., 2019) was assessed on a 11-point scale $\left(0=\right.$ Not at all, $1=$ Very much so; $\left.N_{\text {mean }}=45.1\right)$. The beauty scale was comprised of the following items: beautiful, attractive, good-looking, appealing, ugly (reverse scored), pleasing, pretty, exquisite, and hideous (reverse scored). Based on this data, we selected four images of beautiful animals $\left(M_{\text {beauty }}=8.5\right)$ and four images of ugly animals $\left(M_{\text {beauty }}=5.1\right)$ that differed in perceived beauty but were matched in biological categories: birds, fish, insects and mammals (see Figure 3). The images were displayed in a random order.

\section{Figure 3}

Images used in Study 5 a (taken from Possidónio et al., 2019). Beautiful animals are displayed in the top row and ugly animals are displayed in the bottom row.
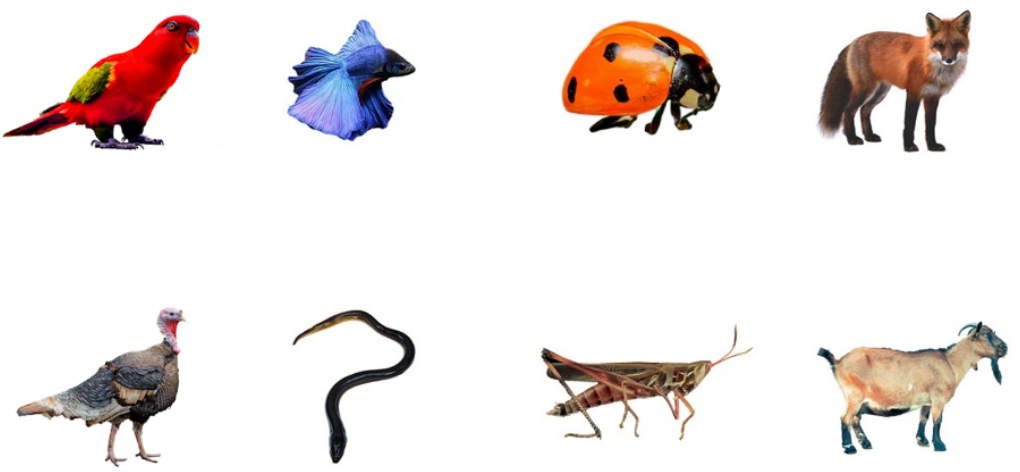
Table 3

Within-subject repeated-measures mediation analysis with condition (beautiful vs. ugly) as independent variable; moral standing as dependent variable; and purity, utility, inspiration, aliveness, age, disgust, sadness and fear as mediators (Study 4).

\begin{tabular}{|c|c|c|c|c|c|c|c|c|c|}
\hline \multirow[b]{2}{*}{ Mediator } & \multicolumn{3}{|c|}{ Condition on Mediator } & \multicolumn{3}{|c|}{ Mediator on Moral Standing } & \multicolumn{3}{|c|}{ Indirect effect } \\
\hline & $b$ & $S E$ & $C I$ & $b$ & $S E$ & $C I$ & $b$ & $S E$ & $C I$ \\
\hline Purity & $2.63^{* * *}$ & 0.12 & {$[2.39,2.86]$} & $0.24^{* * *}$ & 0.06 & {$[0.12,0.35]$} & 0.62 & 0.15 & {$[0.33,0.91]$} \\
\hline Utility & $2.42^{* * *}$ & 0.12 & {$[2.19,2.66]$} & $0.30^{* * *}$ & 0.06 & {$[0.18,0.42]$} & 0.73 & 0.18 & {$[0.38,1.09]$} \\
\hline Inspiration & $1.84^{* * *}$ & 0.12 & {$[1.60,2.07]$} & $0.28^{* * *}$ & 0.06 & {$[0.16,0.40]$} & 0.51 & 0.12 & {$[0.28,0.74]$} \\
\hline Aliveness & $0.91^{* * *}$ & 0.10 & {$[0.70,1.11]$} & -0.02 & 0.05 & {$[-0.13,0.09]$} & -0.02 & 0.06 & {$[-0.12,0.10]$} \\
\hline Age & $10.32^{* * *}$ & 1.04 & {$[8.27,12.36]$} & $0.02^{* * *}$ & 0.005 & {$[0.01,0.03]$} & 0.17 & 0.06 & {$[0.06,0.29]$} \\
\hline Disgust & $-1.47^{* * *}$ & 0.10 & {$[-1.68,-1.27]$} & -0.14 & 0.09 & {$[-0.32,0.05]$} & 0.20 & 0.15 & {$[-0.09,0.50]$} \\
\hline Sadness & $-1.20^{* * *}$ & 0.08 & {$[-1.37,-1.04]$} & -0.06 & 0.09 & {$[-0.24,0.13]$} & 0.07 & 0.10 & {$[-0.11,0.26]$} \\
\hline Fear & $-1.30^{* * *}$ & 0.09 & {$[-1.48,-1.13]$} & -0.02 & 0.09 & {$[-0.19,0.16]$} & 0.02 & 0.14 & {$[-0.28,0.28]$} \\
\hline \multicolumn{7}{|c|}{ Total effect of the condition on moral standing: } & $2.13^{* * *}$ & 0.01 & {$[2.11,2.14]$} \\
\hline \multicolumn{7}{|c|}{ Direct effect of the condition on moral standing: } & -0.17 & 0.15 & {$[-0.46,0.12]$} \\
\hline
\end{tabular}

Model summary: $F(16,270)=28.33, p<.001, R^{2}=.63$

Note. $\mathrm{CI}=95 \%$ Confidence Interval. ${ }^{*} p<.05 .{ }^{* *} p<.01 .{ }^{* * *} p<.001$. 
Moral standing. The moral standing scale was adapted from Piazza et al. (2004). The items were designed to measure whether the animal morally matters to the subject for its own sake. It was comprised of the following items $\left(\alpha_{\text {beautiful }}=.96 ; \alpha_{\text {ugly }}=.96\right)$ : "This animal deserves to be protected from harm"; "This animal deserves to be treated with care and compassion"; "I have respect for this animal"; "Harming this animal is morally wrong"; "This animal has the right to be protected from harm". The last item was included in addition to the original scale as it even more explicitly taps into perceptions about whether the targets matter for their own sake. However, we did not use an item asking about feelings of sympathy for the target because it does not apply to buildings (see Study $5 \mathrm{~b}$ ).

Purity and control variables. The purity scale was comprised of two items $\left(\alpha_{\text {beautiful }}=\right.$ $\left..89 ; \alpha_{\text {ugly }}=.91\right)$ : "This animal makes me think of something pure"; "This animal is pristine". The utility scale was comprised of the following items $\left(\alpha_{\text {beautiful }}=.95 ; \alpha_{\text {ugly }}=.95\right)$ : "This animal is beneficial to me"; "This animal is advantageous to me". Finally, the rarity scale was comprised of the following two items $\left(\alpha_{\text {beautiful }}=.90 ; \alpha_{\text {ugly }}=.92\right)$ : "This animal is rare"; "This animal is scarce". All items were measured using an 11 -point scale $(0=$ not at all, $10=$ very much so) and the order in which the items were presented was randomised.

\section{Results}

Five participants were excluded from the analyses. Three failed the attention check and two denied the usage of their data.

Mediation analysis. ${ }^{8}$ A mediation analysis as in the previous studies was conducted. The model was significant, $F(2,290)=48.36, p<.001, R^{2}=.25$.

Beautiful animals were assigned more moral standing than ugly animals (beauty $=1$; ugliness $=0), b=1.13, S E=0.07, t(292)=17.23,95 \% \mathrm{CI}=[1.00,1.26]$. Furthermore, beauty

\footnotetext{
${ }^{8}$ We inadvertently did not include a manipulation check in this study. However, differences in perceived beauty between the sets of images was validated in a separate study (see above).
} 
(vs. ugliness) positively predicted purity, $b=2.41, S E=0.09,95 \% \mathrm{CI}=[2.23,2.59]$, and purity positively predicted moral standing, $b=0.35, S E=0.04,95 \% \mathrm{CI}=[0.28,0.42]$. As predicted, there was a significant indirect effect of beauty on moral standing through perceptions of purity, $b=0.85, S E=0.13,95 \% \mathrm{CI}=[0.61,1.10]$. There was also a direct effect of beauty (vs. ugliness) on moral standing, $b=0.28, S E=0.10, t(290)=2.68,95 \% \mathrm{CI}=$ $[0.07,0.49]$.

When adding perceived utility and rarity as parallel mediators to the model, the indirect effect of beauty (vs. ugliness) on moral standing via purity remained significant, $b=$ $0.72, S E=0.13,95 \% \mathrm{CI}=[0.48,0.99]$ (for full statistics, see supplemental materials).

Furthermore, perceived rarity significantly mediated the effect of beauty on moral standing, $b$ $=0.26, S E=0.09,95 \% \mathrm{CI}=[0.10,0.43]$. In contrast to previous studies, however, utility was a non-significant mediator, $b=-0.01, S E=0.01,95 \% \mathrm{CI}=[-0.03,0.01]$.

\section{Study 5b}

Study 5a replicated the finding that people attribute more moral standing to beautiful compared to ugly animals mediated by purity intuitions, using a direct measure of moral standing and an expanded measure of purity. Utility, however, was not a significant mediator. Furthermore, we found perceived rarity to significantly and positively mediate the effect which is inconsistent with research linking beauty to averageness (Halberstadt \& Rhodes, 2000). In Study 5b, we aimed to replicate the findings of Study 4 showing that people attribute moral standing to beautiful buildings (i.e., non-sentient entities), using the same direct measure of moral standing.

\section{Method}

Participants. Consistent with previous studies, we recruited 300 participants (175 female, 124 male, 1 other gender; $M_{a g e}=38.3, S D=12.4$, range $\left.=18-69\right)$ living in the UK 
from Prolific. The compensation was $£ 0.65$. The pre-registration can be accessed at https://aspredicted.org/blind.php? $\mathrm{x}=\mathrm{g} 3 \mathrm{i} 6 \mathrm{zt}$.

Procedure and Materials. We used the same design and items as in Study 5a but presented participants with the eight images of buildings from Study 4 . The reliabilities of the scales were high $(\alpha \mathrm{s}=.78-.96)$.

\section{Results}

Five participants were excluded from the analyses because they failed the attention check and one because they did not consent to the usage of their data.

Manipulation checks. A paired-sample $t$-test revealed that beautiful buildings $(M=$ $6.5, S D=1.6)$ were perceived as significantly more beautiful than ugly buildings $(M=3.2$, $S D=2.1), t(293)=27.12, p<.001$.

Mediation analysis. A mediation analysis as in the previous studies was conducted. The model was significant, $F(2,291)=216.22, p<.001, R^{2}=.60$. Participants attributed more moral standing to beautiful animals compared to ugly animals (beauty $=1$; ugliness $=$ $0), b=1.61, S E=0.10, t(293)=16.61,95 \% \mathrm{CI}=[1.42,1.80]$. Furthermore, beauty (vs. ugliness) positively predicted purity, $b=2.54, S E=0.10,95 \% \mathrm{CI}=[2.34,2.74]$, and purity positively predicted moral standing, $b=0.72, S E=0.04,95 \% \mathrm{CI}=[0.65,0.79]$. There was also a significant indirect effect of beauty on moral standing through purity, $b=0.85, S E=$ $0.13,95 \% \mathrm{CI}=[0.61,1.10]$. There was, however, no direct effect of beauty (vs. ugliness) on moral standing, $b=-0.21, S E=0.11, t(291)=-1.95,95 \% \mathrm{CI}=[-0.42,0.002]$.

When adding perceived utility and rarity as parallel mediators to the model, purity remained a significant mediator of beauty (vs. ugliness) on moral standing, $b=1.35, S E=$ $0.13,95 \% \mathrm{CI}=[1.11,1.62]$ (for full statistics, see supplemental materials). Furthermore, perceived utility significantly mediated the effect of beauty on moral standing, $b=0.31, S E=$ 
$0.07,95 \% \mathrm{CI}=[0.18,0.44]$. In contrast to Study $5 \mathrm{a}$, perceived rarity negatively mediated the effect, $b=-0.40, S E=0.06,95 \% \mathrm{CI}=[-0.51,0.29]$.

\section{General Discussion}

A long philosophical tradition has linked beauty to morality (e.g., Socrates and Kant). Extending previous research suggesting people may attribute more moral standing to beautiful (vs. ugly) humans and animals (e.g., Gunnthorsdottir, 2001; Langlois et al., 2000), the present studies provided empirical evidence that people attribute moral standing to a wide range of beautiful targets including both sentient beings (humans and animals), and nonsentient entities (landscapes and buildings). Furthermore, across all studies, we found purity intuitions to mediate the effect of beauty (vs. ugliness) on moral standing attributions. As such, we provided initial empirical evidence for purity intuitions as a psychological mechanism through which people view beautiful entities as possessing moral standing.

In Studies 1-4, we measured moral standing through an intuitive measure (i.e., expressed desire to protect). In these studies, we found perceived utility to be a second pathway mediating the effect of beauty (vs. ugliness) on the desire to protect the target. This suggests that people want to protect beautiful entities due to their instrumental value, consistent with theorizing which argues beauty is linked to adaptive value (Dutton, 2009). In Studies $5 \mathrm{a}$ and $5 \mathrm{~b}$, we used a more direct measure of moral standing that directly assessed whether the entities matter for their own sake (Sytsma \& Machery, 2012). In Study 5a, utility was a non-significant mediator, and in Study 5b, utility was a significant mediator of the observed effect (but considerably weaker than purity). Moreover, we found alternative pathways through which beauty increases moral standing attributions that were not consistent across studies but appear to be more idiosyncratic to specific targets. First, beautiful landscapes were perceived to possess more moral standing than ugly landscapes because they appeared more alive. Second, beautiful buildings were attributed more moral standing 
because they were perceived to be older than ugly buildings. Third, beautiful landscapes and buildings (but not animals and humans) were perceived to be more worthy of protection than their ugly counterparts because they were found to be inspiring. Fourth, consistent with the evidence showing that average objects are typically considered to be more beautiful than nonaverage objects (Halberstadt \& Rhodes, 2000), perceived rarity of buildings was found to negatively mediate the effect of beauty (vs. ugliness) on moral standing attributions. However, inconsistent with this finding, perceived rarity of animals was a positive mediator of the observed effect.

The present findings add to past research identifying several factors which contribute to whether people view entities as possessing moral standing. For example, it has been argued that mind perception is the essence of morality and thus that the capacity to suffer is crucial for considering targets as worthy of protection (Gray et al., 2012). This is also reflected in the ethical theory of utilitarianism which places sentience in the centre of moral considerations (Singer, 1979). Building on previous research which suggests that people may attribute moral standing to beautiful humans (Dion et al., 1972; Langlois et al., 2000) and animals (Gunnthorsdottir, 2001; Marešová \& Frynta, 2008; Landová et al., 2018), we proposed that beauty may be another factor that increases the moral standing people attribute to entities. We found that - beyond mind perception — people attribute moral standing to both beautiful sentient beings (humans and animals) and beautiful non-sentient entities (landscapes and buildings). This is consistent with anecdotal evidence showing that the destruction of beautiful non-sentient entities may cause outrage even if they are lacking utility to humans or are replaced by something more useful. For example, in 2018 the decision to clear an old-growth forest for coal mining caused public outrage in Germany (Willkes \& Parkin, 2018). This view that non-sentient targets have moral standing beyond their usefulness for human purposes was popularized by the deep ecology movement (Naess, 
1986) and the philosopher Tom Regan who argued that "nonconscious natural objects can have value in their own right, independently of human interests” (Regan, 1981, p.1).

Finally, our findings have practical implications for individuals who seek to increase people's moral concern for entities and particularly for targets that do not have the capacity to suffer. In environmental psychology, biospheric value orientation is one of the most widely used constructs to operationalize people's concern for plants and animals which is independent from their utility to oneself or other humans (Stern \& Dietz, 1994). The present findings suggest that perceptions of beauty may be one contributor to biospheric concern. Furthermore, in order to identify flagship species used in fundraising campaigns, international conservation NGOs take into account species' aesthetic appeal (Smith et al., 2012). Understanding the mechanism through which beauty increases moral concern may contribute to these efforts to increase moral concern for wildlife and ecosystems.

\section{Limitations and Future Directions}

The present studies have investigated differences in the moral standing people attribute to beautiful compared to ugly entities. Further research is needed to examine whether there is a threshold over which an entity is attributed moral standing or whether moral standing placed on targets increases gradually from ugly to beautiful targets. Furthermore, evidence regarding the directionality of the observed effect remains inconclusive. Across all studies, purity consistently mediated the effect of beauty (vs. ugliness) on moral standing attributions, while disgust experiences did not mediate the effect in any of the studies. This suggests that beauty increases moral standing attributions through eliciting purity intuitions. However, this interpretation is limited by the fact that in Studies 14, ugliness ratings of ugly images were below or only slightly above the mid-point of the scale. This leaves open the possibility that in addition to beauty increasing the moral standing placed on entities, ugliness may decrease moral standing of ugly compared to average- 
looking targets by eliciting the emotion of disgust (Klebl et al., 2020; Ryan et al., 2012). This possibility is consistent with evidence suggesting that the Beauty-is-Good stereotype may be driven by the lower end of the attractiveness spectrum (Griffin \& Langlois, 2006; Jaeger et al., 2018), and thus should be explored in future research.

Future research is also needed to better understand the purity pathway through which beauty increases moral standing. While the present investigation provides initial evidence for purity intuitions as the mechanism through which beauty perceptions lead to moral standing attributions, there are remaining questions regarding the nature of this pathway. For example, the nature of aesthetic purity intuitions is little understood. There may be low-level features underlying beauty perceptions (e.g., symmetry or typicality) that are specifically associated with purity perceptions and as such, may underlie the assignment of moral standing to beautiful entities. Another remaining question is whether there are boundary conditions of the effect of beauty (vs. ugliness) on moral standing attributions. For example, it should be examined whether the effect extends to an even broader range of targets, including abstract forms, beautiful music or art. Furthermore, the conditions under which people do not place a higher moral standing on beautiful targets should be identified. Finally, future research is needed to find avenues through which to counteract the bias of attributing greater moral standing to beautiful targets and as such, through which to increase moral concern for ugly targets.

\section{Conclusion}

We found support for people attributing moral standing to both beautiful sentient and non-sentient targets. Therefore, beauty perceptions signal that targets are worthy of protection independent from their utility, and this is explained by an intuitive association between beauty and purity. Our findings also suggest novel and practical avenues through which to 
leverage moral concern for a wide range of targets such as animals, plants, or works of architecture.

\section{Disclosure of data collection and analysis}

The data and materials of all studies are available at https://osf.io/uqgt4/?view_only $=402591826 a 5040 f 8 a 24 d 948 d f 3 a 346 d 7$. We confirm that all measures, conditions, data exclusions and methods of determining sample sizes were reported. 


\section{References}

Avram, M., Gutyrchik, E., Bao, Y., Pöppel, E., Reiser, M., \& Blautzik, J. (2013).

Neurofunctional correlates of esthetic and moral judgments. Neuroscience Letters, 534, 128-132. https://dx.doi.org/10.1016/j.neulet.2012.11.053.

Baron, J., \& Spranca, M. (1997). Protected values. Organizational Behavior and Human Decision Processes, 70(1), 1-16. https://dx.doi.org/10.1006/obhd.1997.2690.

Bascandziev, I., \& Harris, P. L. (2014). In beauty we trust: Children prefer information from more attractive informants. British Journal of Developmental Psychology, 32(1), 9499. https://doi.org/10.1111/bjdp.12022.

Bastian, B., Laham, S. M., Wilson, S., Haslam, N., \& Koval, P. (2011). Blaming, praising, and protecting our humanity: The implications of everyday dehumanization for judgments of moral status. British Journal of Social Psychology, 50(3), 469-483. http://dx.doi.org/10.1348/014466610X521383.

Diessner, R., Iyer, R., Smith, M., \& Haidt, J. (2013). Who engages with moral beauty? Journal of Moral Education, 42, 139-163. doi:10.1080/03057240.2013.785941.

Dion, K., Berscheid, E., \& Walster, E. (1972). What is beautiful is good. Journal of Personality and Social Psychology, 24(3), 285-290. http://dx.doi.org/10.1037/h0033731.

Dutton, D. (2009). The art instinct: Beauty, pleasure, \& human evolution. New York: Oxford University Press.

Feinberg, M., \& Willer, R. (2013). The moral roots of environmental attitudes. Psychological Science, 24(1), 56-62. http://dx.doi.org/10.1177\%2F0956797612449177.

Frimer, J. A., Tell, C. E., \& Haidt, J. (2015). Liberals condemn sacrilege too: The harmless desecration of Cerro Torre. Social Psychological and Personality Science, 6(8), 878886. https://doi.org/10.1177/1948550615597974 
Gerson, L. (Ed.). (2017). Plotinus: The Enneads (G. Boys-Stones, J. Dillon, R. King, A. Smith, \& J. Wilberding, Trans.). Cambridge: Cambridge University Press. doi:10.1017/9780511736490

Goodwin, G. P. (2015). Experimental approaches to moral standing. Philosophy Compass, 10(12), 914-926. https://doi.org/10.1111/phc3.12266.

Gray, K., Young, L., \& Waytz, A. (2012). Mind perception is the essence of morality. Psychological Inquiry, 23(2), 101-124. https://dx.doi.org/10.1080/1047840X.2012.651387.

Gray, K., \& Wegner, D. M. (2009). Moral typecasting: divergent perceptions of moral agents and moral patients. Journal of Personality and Social Psychology, 96(3), 505-520. https://psycnet.apa.org/doi/10.1037/a0013748.

Gunnthorsdottir, A. (2001). Physical attractiveness of an animal species as a decision factor for its preservation. Anthrozoös, 14(4), 204-215. https://doi.org/10.2752/089279301786999355.

Haidt, J. (2003). Elevation and the positive psychology of morality. In C. L. M. Keyes \& J. Haidt (Eds.), Flourishing: Positive psychology and the life well-lived (pp. 275-289). Washington, DC: American Psychological Association.

Haidt, J., \& Graham, J. (2007). When morality opposes justice: Conservatives have moral intuitions that liberals may not recognize. Social Justice Research, 20(1), 98-116. https://doi.org/10.1007/s11211-007-0034-z.

Haidt, J., \& Joseph, C. (2004). Intuitive ethics: How innately prepared intuitions generate culturally variable virtues. Daedalus, 133(4), 55-66. https://dx.doi.org/10.1162/0011526042365555. 
Halberstadt, J., \& Rhodes, G. (2000). The attractiveness of nonface averages: Implications for an evolutionary explanation of the attractiveness of average faces. Psychological Science, 11(4), 285-289. https://doi.org/10.1111\%2F1467-9280.00257.

Heinzelmann, N. C., Weber, S. C., \& Tobler, P. N. (2020). Aesthetics and morality judgments share cortical neuroarchitecture. Cortex, 129, 484-495. https://doi.org/10.1016/j.cortex.2020.04.018.

Jaeger, B., Wagemans, F. M., Evans, A. M., \& van Beest, I. (2018). Effects of facial skin smoothness and blemishes on trait impressions. Perception, 47(6), 608-625. https://doi.org/10.1177\%2F0301006618767258

Kant, I. (2000). Critique of the Power of Judgment. Ed. Paul Guyer \& Eric Matthews. New York, NY: Cambridge University Press. (Original work published in 1790).

Klebl, C., Greenaway, K. H., Rhee, J. J., \& Bastian, B. (2020). Ugliness judgments alert us to cues of pathogen presence. Social Psychological and Personality Science. https://doi.org/10.1177\%2F1948550620931655.

Landová, E., Poláková, P., Rádlová, S., Janovcová, M., Bobek, M., \& Frynta, D. (2018). Beauty ranking of mammalian species kept in the Prague Zoo: Does beauty of animals increase the respondents' willingness to protect them? The Science of Nature, 105(11-12), 69.

Langlois, J. H., Kalakanis, L., Rubenstein, A. J., Larson, A., Hallam, M., \& Smoot, M. (2000). Maxims or myths of beauty? A meta-analytic and theoretical review. Psychological Bulletin, 126(3), 390-423. http://dx.doi.org/10.1037/00332909.126.3.390.

Ma, Correll, \& Wittenbrink (2015). The Chicago Face Database: A Free Stimulus Set of Faces and Norming Data. Behavior Research Methods, 47, 1122-1135. https://dx.doi.org/10.3758/s13428-014-0532-5. 
Marešová, J., \& Frynta, D. (2008). Noah's Ark is full of common species attractive to humans: The case of boid snakes in zoos. Ecological Economics, 64(3), 554-558. https://doi.org/10.1016/j.ecolecon.2007.03.012

Montoya, A. K., \& Hayes, A. F. (2017). Two-condition within-participant statistical mediation analysis: A path-analytic framework. Psychological Methods, 22(1), 6-27. http://dx.doi.org/10.1037/met0000086.

Naess, A. (1986). The deep ecological movement: Some philosophical aspects. Philosophical Inquiry, 8, 10-31. https://doi.org/10.5840/philinquiry198681/22.

Oaten, M., Stevenson, R. J., \& Case, T. I. (2011). Disease avoidance as a functional basis for stigmatization. Philosophical Transactions of the Royal Society B: Biological Sciences, 366(1583), 3433-3452. https://doi.org/10.1098/rstb.2011.0095

Park, J. H., Van Leeuwen, F., \& Chochorelou, Y. (2013). Disease-avoidance processes and stigmatization: Cues of substandard health arouse heightened discomfort with physical contact. The Journal of Social Psychology, 153(2), 212-228. https://doi.org/10.1080/00224545.2012.721812

Piazza, J., Landy, J. F., \& Goodwin, G. P. (2014). Cruel nature: Harmfulness as an important, overlooked dimension in judgments of moral standing. Cognition, 131(1), 108-124. https://dx.doi.org/10.1016/j.cognition.2013.12.013.

Possidónio, C., Graça, J., Piazza, J., \& Prada, M. (2019). Animal images database: validation of 120 images for human-animal studies. Animals, 9(8), 475. https://doi.org/10.3390/ani9080475.

Regan, T. (1981). The nature and possibility of an environmental ethic. Environmental Ethics, 3(1), 19-34. http://dx.doi.org/ 10.5840/enviroethics19813131. 
Rottman, J., Kelemen, D., \& Young, L. (2015). Hindering harm and preserving purity: How can moral psychology save the planet? Philosophy Compass, 10(2), 134-144. http://dx.doi.org/10.1111/phc3.12195.

Rozin, P., \& Ruby, M. B. (2020). Bugs are blech, butterflies are beautiful, but both are bad to bite: Admired animals are disgusting to eat but are themselves neither disgusting nor contaminating. Emotion, 20(5), 854-865. https://psycnet.apa.org/doi/10.1037/emo0000587.

Ruby, M. B., \& Heine, S. J. (2012). Too close to home. Factors predicting meat avoidance. Appetite, 59(1), 47-52. https://doi.org/10.1016/j.appet.2012.03.020

Ruttan, R. L., \& Nordgren, L. F. (2021). Instrumental use erodes sacred values. Journal of Personality and Social Psychology. Advance online publication. https://doi.org/10.1037/pspi0000343

Ryan, S., Oaten, M., Stevenson, R. J., \& Case, T. I. (2012). Facial disfigurement is treated like an infectious disease. Evolution and Human Behaviour, 33(6), 639-646. https://doi.org/10.1016/j.evol humbehav.2012.04.001

Rzymski, C., Tresoldi, T., Greenhill, S. J., Wu, M. S., Schweikhard, N. E., KoptjevskajaTamm, M., ... \& Chang, S. (2020). The Database of Cross-Linguistic Colexifications, reproducible analysis of cross-linguistic polysemies. Scientific Data, 7(1), 1-12. http://dx.doi.org/ 10.1038/s41597-019-0341-x.

Schoemann, A. M., Boulton, A. J., \& Short, S. D. (2017). Determining power and sample size for simple and complex mediation models. Social Psychological and Personality Science, 8(4), 379-386. http://dx.doi.org/10.1177/1948550617715068.

Sherman, G. D., Haidt, J., \& Coan, J. A. (2009). Viewing cute images increases behavioral carefulness. Emotion, 9(2), 282-286. http://dx.doi.org/ 10.1037/a0014904. 
Smith, R. J., Veríssimo, D., Isaac, N. J., \& Jones, K. E. (2012). Identifying Cinderella species: Uncovering mammals with conservation flagship appeal. Conservation Letters, 5(3), 205-212. http://dx.doi.org/10.1111/j.1755-263X.2012.00229.x.

Singer, P. (1979). Practical ethics. UK: Cambridge University Press.

Stern, P. C., \& Dietz, T. (1994). The value basis of environmental concern. Journal of Social Issues, 50(3), 65-84. http://dx.doi.org/10.1111/j.1540-4560.1994.tb02420.x.

Stern, P. C., Dietz, T., Abel, T., Guagnano, G. A., \& Kalof, L. (1999). A value-belief-norm theory of support for social movements: The case of environmentalism. Human Ecology Review, 6, 81-97.

Sytsma, J., \& Machery, E. (2012). The two sources of moral standing. Review of Philosophy and Psychology, 3(3), 303-324. http://dx.doi.org/ 10.1007/s13164-012-0102-7.

Tangney, J. P., Stuewig, J., \& Mashek, D. J. (2007). Moral emotions and moral behavior. Annual Review of Psychology, 58, 345-372. http://dx.doi.org/10.1146/annurev.psych.56.091103.070145.

Tetlock, P. E., Kristel, O. V., Elson, S. B., Green, M. C., \& Lerner, J. S. (2000). The psychology of the unthinkable: taboo trade-offs, forbidden base rates, and heretical counterfactuals. Journal of Personality and Social Psychology, 78(5), 853-870. http://dx.doi.org/10.1037//0022-3514.78.5.853.

Thorndike, E. L. (1920). A constant error in psychological ratings. Journal of Applied Psychology, 4(1), 25-29.

Thrash, T. M., \& Elliot, A. J. (2003). Inspiration as a psychological construct. Journal of Personality and Social Psychology, 84(4), 871-889. http://dx.doi.org/10.1037/00223514.84.4.871. 
Tisdell, C., Nantha, H. S., \& Wilson, C. (2007). Endangerment and likeability of wildlife species: How important are they for payments proposed for conservation? Ecological Economics, 60(3), 627-633. https://doi.org/10.1016/j.ecolecon.2006.01.007.

Tsukiura, T., \& Cabeza, R. (2010). Shared brain activity for aesthetic and moral judgments: implications for the Beauty-is-Good stereotype. Social Cognitive and Affective Neuroscience, 6(1), 138-148. http://dx.doi.org/10.1093/scan/nsq025.

Wang, T., Mo, L., Mo, C., Tan, L. H., Cant, J. S., Zhong, L., \& Cupchik, G. (2015). Is moral beauty different from facial beauty? Evidence from an fMRI study. Social Cognitive and Affective Neuroscience, 10(6), 814-823. http://dx.doi.org/10.1093/scan/nsu123.

Willkes, W., \& Parkin, B. (2018, December 3). A Coal Mine Is Devouring a 12,000-Year-Old Forest. Retrieved from https://www.bloomberg.com/features/2018-hambach-forest/ 